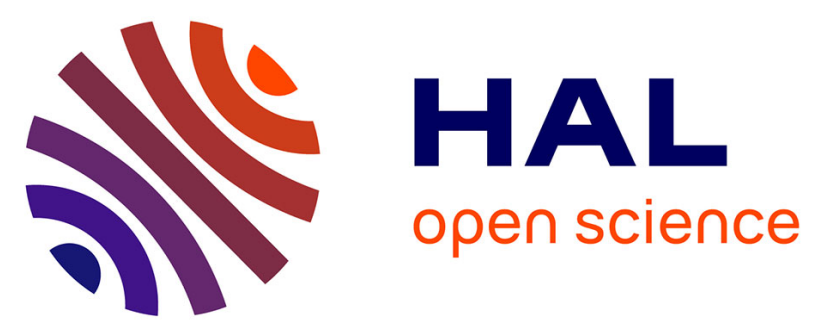

\title{
Spontaneous galvanic deposition of nanoporous Pd on microfibrous-structured Al-fibers for CO oxidative coupling to dimethyl oxalate
}

Chunzheng Wang, Weisong Xu, Zhengxing Qin, Svetlana Mintova

\section{To cite this version:}

Chunzheng Wang, Weisong Xu, Zhengxing Qin, Svetlana Mintova. Spontaneous galvanic deposition of nanoporous $\mathrm{Pd}$ on microfibrous-structured Al-fibers for $\mathrm{CO}$ oxidative coupling to dimethyl oxalate. Catalysis Communications, 2019, 119, pp.39-41. 10.1016/j.catcom.2018.10.014 . hal-02409994

\author{
HAL Id: hal-02409994 \\ https://hal.science/hal-02409994
}

Submitted on 27 Nov 2020

HAL is a multi-disciplinary open access archive for the deposit and dissemination of scientific research documents, whether they are published or not. The documents may come from teaching and research institutions in France or abroad, or from public or private research centers.
L'archive ouverte pluridisciplinaire HAL, est destinée au dépôt et à la diffusion de documents scientifiques de niveau recherche, publiés ou non, émanant des établissements d'enseignement et de recherche français ou étrangers, des laboratoires publics ou privés. 
Spontaneous galvanic deposition of nanoporous Pd on microfibrous-structured Al-fibers for CO oxidative coupling to dimethyl oxalate

Chunzheng Wang ${ }^{\mathrm{a},{ }^{*}}$, Weisong $\mathrm{Xu}^{\mathrm{a}}$, Zhengxing Qin ${ }^{\mathrm{a}}$, Svetlana Mintova ${ }^{\mathrm{a}, \mathrm{b}}$

${ }^{a}$ State Key Laboratory of Heavy Oil Processing, College of Chemical Engineering, China University of Petroleum (East China), Qingdao 266580, China

${ }^{\mathrm{b}}$ Laboratoire Catalyse et Spectrochimie (LCS), Normandie Université, ENSICAEN, UNICAEN,

CNRS, 6 boulevard Maréchal Juin, Caen 14050, France

* Corresponding author. E-mail: czwang@upc.edu.cn 


\section{Abstract}

Nanoporous palladium (np-Pd) is deposited spontaneously on microfibrous-structured Al-fibers (np-Pd/Al-fiber catalyst) via the galvanic replacement between $\mathrm{Pd}^{2+}$ and aluminium metal $(2 \mathrm{Al}+3$ $\left.\mathrm{Pd}^{2+} \rightarrow 2 \mathrm{Al}^{3+}+3 \mathrm{Pd}\right)$. The np-Pd/Al-fiber catalyst combines the high activity and good stability of the np-Pd with the excellent heat conductivity and large permeability of the microfibrous-structured Al-fibers. The np-Pd/Al-fiber catalyst shows four times higher intrinsic activity (i.e., turnover frequency) than the conventional $\mathrm{Pd} / \alpha-\mathrm{Al}_{2} \mathrm{O}_{3}$ catalyst. The unique nanoporous palladium with interpenetrating network of nanoligaments is responsible for the improved activity in the $\mathrm{CO}$ oxidative coupling to dimethyl oxalate $\left(2 \mathrm{CH}_{3} \mathrm{ONO}+2 \mathrm{CO} \rightarrow 2 \mathrm{NO}+\mathrm{CH}_{3} \mathrm{OCOCOOCH}_{3}\right)$.

Keywords: nanoporous palladium; galvanic deposition; microfibrous-structured catalyst; aluminium fiber; dimethyl oxalate. 


\section{Introduction}

Nanoporous palladium (np-Pd) is of great fundamental and technological importance for wide applications in catalysis, energy storage, sensors and fuel cells [1-3]. Various unsupported np-Pd samples have been successfully prepared by dealloying, consolidation, combustion, hydrothermal growth and template synthesis [4,5]. The fabricated np-Pd possesses high surface-to-volume ratio, interpenetrating nanostructure and large characteristic lengths in nanoligaments [1]. Owing to the special surface effect and resistance to sintering, the np-Pd exhibits good activity and stability in heterogeneous reactions [2,3]. Nevertheless, the high cost of the unsupported np-Pd hinders its practical application, and the as-made powder cannot satisfy the requirements of conventional fixed-bed reactors.

Aluminium metal is inexpensive, highly thermal-conductive, and is so soft that it could be easily made into different microstructured packings such as fibers and foams. These packings are opening avenues to "ideal" catalytic reactors with advantages of high throughput, low pressure drop and improved heat/mass transfer [6,7]. However, the real application of the microstructured $\mathrm{Al}$ metal as reactor packings is hampered by the inert surface and low surface area [8]. Recently, boehmite nanosheets were in-situ generated on microfibrous-structured Al-fibers by the hydrothermal oxidation $\left(4 \mathrm{H}_{2} \mathrm{O}+2 \mathrm{Al} \rightarrow 3 \mathrm{H}_{2}+2 \mathrm{AlOOH}\right)$, and then incipiently impregnated with palladium precursor to obtain the Pd catalyst [9]. Therefore, it is important to find a direct and an effective way to functionalize aluminium metal.

The vapor phase carbonylation of methyl nitrite $(\mathrm{MN})$ to dimethyl oxalate (DMO), a process converting inorganic $\mathrm{C} 1$ to organic $\mathrm{C} 2$ plays a key role from syngas to ethylene glycol (product of DMO hydrogenation) [10,11]. This process involves two main reactions: (1) Pd-catalyzed CO 
oxidative coupling: $2 \mathrm{CH}_{3} \mathrm{ONO}+2 \mathrm{CO} \rightarrow 2 \mathrm{NO}+\mathrm{CH}_{3} \mathrm{OCOCOOCH}_{3}$; and (2) $\mathrm{MN}$ regeneration without catalyst: $2 \mathrm{NO}+2 \mathrm{CH}_{3} \mathrm{OH}+1 / 2 \mathrm{O}_{2} \rightarrow 2 \mathrm{CH}_{3} \mathrm{ONO}+\mathrm{H}_{2} \mathrm{O}$. Although this process has been applied at industrial scale, the commercial $\mathrm{Pd} / \alpha-\mathrm{Al}_{2} \mathrm{O}_{3}$ catalyst needs a high $\mathrm{Pd}$ content of 2 wt $\%$ (the-state-of-the-art) [12]. Decreasing the Pd content is an on-going effort which could be achieved by tuning the Pd shape/size and adding of a promoter on the CO oxidative coupling to DMO [13,14]. However, little attention is paid to the $\alpha-\mathrm{Al}_{2} \mathrm{O}_{3}$ support used, which suffers from poor mass/heat transfer and non-regular flow pattern for the strongly exothermic and fast reaction.

Herein, we report the preparation of a supported catalyst using nanoporous palladium embedded on microfibrous-structured Al-fibers. We also reveal the top-down, versatile and effective method of the catalyst fabrication through the spontaneous galvanic deposition between $\mathrm{Pd}^{2+}$ and $\mathrm{Al}(2 \mathrm{Al}+3$ $\left.\mathrm{Pd}^{2+} \rightarrow 2 \mathrm{Al}^{3+}+3 \mathrm{Pd}\right)$. The np-Pd/Al-fiber catalyst combines the activity and stability of the np-Pd and improved heat/mass transfer, large permeability originated from the microfibrous-structured Al-fibers.

\section{Experimental}

A large thin-sheet fibrofelt $(2.0 \mathrm{~m}$ length $\times 1.0 \mathrm{~m}$ width $\times \sim 1.3 \mathrm{~mm}$ thickness $)$ with Al-fibers (60 $\mu \mathrm{m}$ diameter, 99.9 wt\% Al; Shanghai Xincai Network-microstructured Material Co. Ltd., China) was employed as pristine catalyst support [9]. Typically, circular shaped Al-fibers (16 mm diameter; Fig. S1) were tailored from the purchased fibrofelt and pre-treated with a $\mathrm{NaOH}$ solution $(0.1 \mathrm{wt} \%)$ at 25 ${ }^{\circ} \mathrm{C}$ to remove the oxide layers $\left(\mathrm{Al}_{2} \mathrm{O}_{3}\right)$ from the surface. After that, palladium was deposited onto the pre-treated Al-fibers with the aid of galvanic replacement between $\mathrm{Pd}^{2+}$ and $\mathrm{Al}\left(2 \mathrm{Al}+3 \mathrm{Pd}^{2+} \rightarrow 2\right.$ $\left.\mathrm{Al}^{3+}+3 \mathrm{Pd}\right)$. This reaction proceeded spontaneously at room temperature when the pre-treated Al-fibers were impregnated with an acetic acid $\left(\mathrm{CH}_{3} \mathrm{COOH}\right)$ solution containing appointed amount 
of palladium acetate $\left(\mathrm{Pd}\left(\mathrm{CH}_{3} \mathrm{COO}\right)_{2}\right.$; Sinopharm Chemical Reagent Co. Ltd., China). During the galvanic process, the orange solution gradually became clear. The resulting Al-fibers were dried at $100{ }^{\circ} \mathrm{C}$ for $2 \mathrm{~h}$, followed by calcining at $300{ }^{\circ} \mathrm{C}$ (air) for $2 \mathrm{~h}$ to obtain the np-Pd/Al-fiber catalyst. The nominal Pd content in the np-Pd/Al-fiber catalysts was in the range of $0.1-2.0 \mathrm{wt} \%$. In addition, we prepared a reference catalyst of $\mathrm{Pd} / \alpha-\mathrm{Al}_{2} \mathrm{O}_{3}$ (nominal Pd content of $0.3 \mathrm{wt} \%$ ) using incipient-wetness impregnation with $\mathrm{Pd}\left(\mathrm{CH}_{3} \mathrm{COO}\right)_{2}$ as a precursor and $\alpha-\mathrm{Al}_{2} \mathrm{O}_{3}$ (Alfa Aesar (China) Chemical Co. Ltd.) as a support, followed by drying at $100{ }^{\circ} \mathrm{C}$ for $2 \mathrm{~h}$ and calcination at $300{ }^{\circ} \mathrm{C}$ in air for $2 \mathrm{~h}$. The details of catalyst characterizations and the calculations of the turnover frequency (TOF), conversion and selectivity are available in the Supporting Information (SI).

\section{Results and discussion}

The strategy for preparation of the microfibrous-structured np-Pd/Al-fiber catalyst is schematically presented in Fig. 1A. The Al-fibers with irregular three-dimensional network and $90 \%$ void volume, are used as pristine catalyst support (Fig. 1A and Fig. S1). The original surface of the Al-fibers is smooth, as shown in the SEM images (Fig. S2). After the spontaneous deposition carried out at room temperature through the galvanic replacement between $\mathrm{Pd}^{2+}$ and $\mathrm{Al}\left(2 \mathrm{Al}+3 \mathrm{Pd}^{2+} \rightarrow 2\right.$ $\mathrm{Al}^{3+}+3 \mathrm{Pd}$ ), tree-like np-Pd is epitaxially formed on the Al-fibers surface (Fig. 1B). The circular shape of Al-fibers remains intact (Fig. S1). Both SEM and TEM images show that the np-Pd is composed of 10-30 nm ligaments surrounded by irregular nanopores having a wide size distribution (Fig. 1C,D). The EDX spectra of the np-Pd contain three peaks corresponding to $\mathrm{Pd}, \mathrm{Al}$ and $\mathrm{O}$ with an average content of 90.8, 3.0 and $6.2 \mathrm{wt} \%$, respectively (Fig. S3). The presence of $\mathrm{Al}$ and $\mathrm{O}$ is attributed to the Al substrate and the oxidation of the np-Pd and Al, respectively. The XRD patterns show that only the characteristic diffraction peaks of Al (JCPDS 04-0787) are identified in the 
mother Al-fibers support (Fig. S4). For the np-Pd/Al-fiber catalyst, the diffraction peaks of Pd(200) (JCPDS 01-1201) and PdO(101) (JCPDS 88-2434) are weak, possibly due to the low Pd content (Fig. S4). The PdO phase is formed unavoidably due to the oxidation of the np-Pd during the calcination (see Experimental section), which is consistent with the EDX elemental mapping results (Fig. S3 and Fig. S4). Such PdO can be completely reduced below $25^{\circ} \mathrm{C}$ due to the undetectable $\mathrm{H}_{2}$ consumption above $25{ }^{\circ} \mathrm{C}$ studied by $\mathrm{H}_{2}$-temperature programmed reduction (Fig. S5). The nominal Pd content is $0.5 \mathrm{wt} \%$, while the actual content is $0.28 \mathrm{wt} \%$ measured by ICP-AES analysis. The loss of Pd is occurred during the galvanic deposition; a visible black powder at the bottom of the galvanic solution was observed. The black powder has nanoporous structure similar to the np-Pd observed on the np-Pd/Al-fiber catalyst (Fig. 1C and Fig. S6). Medium dispersion (D) of Pd is measured to be 0.09 by $\mathrm{CO}$ pulse chemisorption measurements, and the particle size $(d)$ is determined to be $\sim 12 \mathrm{~nm}(d=$ $1.12 / D[15]$ ), which is smaller than the size obtained by TEM (average particle size of $19 \mathrm{~nm}$; Fig. 1D).

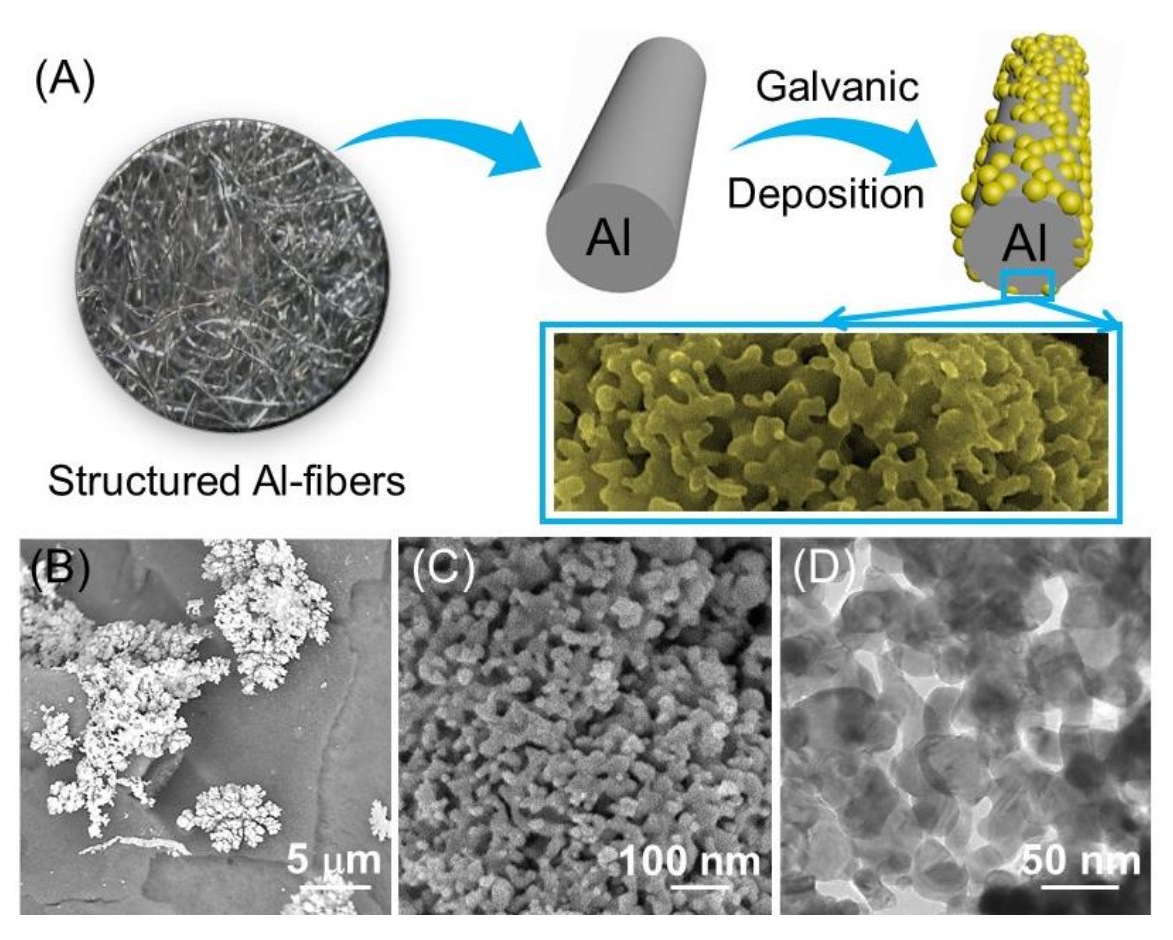

Fig. 1. (A) Strategy applied for preparation of the np-Pd/Al-fiber catalyst by spontaneous galvanic 
deposition. (B-C) SEM and (D) TEM images of the np-Pd/Al-fiber catalyst $(0.28 \mathrm{wt} \% \mathrm{Pd}$, ICP-AES).

As noted previously, the process of spontaneous galvanic deposition includes the following two steps: (1) $\mathrm{Al} \rightarrow \mathrm{Al}^{3+}+3 \mathrm{e}^{-}$and (2) $\mathrm{Pd}^{2+}+2 \mathrm{e}^{-} \rightarrow \mathrm{Pd}$. The galvanic deposition proceeds automatically at room temperature once the Al-fibers are impregnated with the $\mathrm{CH}_{3} \mathrm{COOH}$ solution of $\operatorname{Pd}\left(\mathrm{CH}_{3} \mathrm{COO}\right)_{2}$. The driving force of this reaction is the large difference in electrode potential between $\mathrm{Al}^{3+} / \mathrm{Al}^{0}(-1.66 \mathrm{~V})$ and $\mathrm{Pd}^{2+} / \mathrm{Pd}^{0}(0.91 \mathrm{~V})$ pairs. Palladium is first nucleated and deposited at energy-favorable sites or dislocation centers on the Al-fibers surface [16]. With prolonged time of galvanic deposition, the palladium is epitaxially formed on the Al-fiber and assembled as np-Pd, which is confirmed by SEM-EDX analysis (Fig. S7).

The effect of the nominal Pd content on the catalytic activity of the np-Pd/Al-fiber in the CO oxidative coupling to DMO was studied (Fig. S8). Clearly, with the increase of Pd content from 0.1 to $0.5 \mathrm{wt} \%$, at $150{ }^{\circ} \mathrm{C}$, the $\mathrm{CO}$ conversion is increased from $31.3 \%$ to $55.6 \%$ and gradually increased to $65.5 \%$ with further rising of the Pd content up to $2.0 \mathrm{wt} \%$. While the DMO selectivity ( 95\%) is almost independent of the $\mathrm{Pd}$ content. Based on the balance between the $\mathrm{CO}$ conversion and the catalyst cost, the optimal Pd content of $0.5 \mathrm{wt} \%$ was identified, while the actual one is $0.28 \mathrm{wt} \%$.

As shown in Fig. 2A, the np-Pd/Al-fiber catalyst shows higher DMO selectivity than the conventional $\mathrm{Pd} / \alpha-\mathrm{Al}_{2} \mathrm{O}_{3}$ catalyst. Both catalysts show a volcano-type variation of $\mathrm{CO}$ conversion by elevating the reaction temperature from 120 to $170{ }^{\circ} \mathrm{C}$. The np-Pd/Al-fiber catalyst reaches a maximal $\mathrm{CO}$ conversion at $160{ }^{\circ} \mathrm{C}$ while the $\mathrm{Pd} / \alpha-\mathrm{Al}_{2} \mathrm{O}_{3}$ catalyst at $140{ }^{\circ} \mathrm{C}$, which indirectly indicates the effect of the structure for np-Pd on Al-fibers and Pd nanoparticles on $\alpha-\mathrm{Al}_{2} \mathrm{O}_{3}$. The actual $\mathrm{Pd}$ content and Pd oxidation state are similar for both catalysts, but Pd dispersion and surface Pd atoms 
of the np-Pd/Al-fiber catalyst are much lower than for the $\mathrm{Pd} / \alpha-\mathrm{Al}_{2} \mathrm{O}_{3}$ (Table 1 , XPS spectra in Fig. S9). However, the np-Pd/Al-fiber catalyst exhibits a TOF of $1.2 \mathrm{~s}^{-1}$, which is four times higher than for the $\mathrm{Pd} / \alpha-\mathrm{Al}_{2} \mathrm{O}_{3}\left(0.2 \mathrm{~s}^{-1}\right)$, suggesting that the former possesses far larger intrinsic activity on the CO oxidative coupling to DMO. The np-Pd with well-connected network of nanoligaments, possesses nearly equivalent concave and convex surface (negative and positive curvature), thereby leading to lattice contraction and expansion based on the Laplace equation $[17,18]$. The HRTEM images show lattice fringes of $0.208-0.231 \mathrm{~nm}$ that correspond to $\operatorname{Pd}(111)$ facet on some disordered areas for the np-Pd/Al-fiber catalyst (Fig. S10); this result indicates that some lattices are expanded while some are contracted. Such lattice disorder of the np-Pd has a remarkable influence on the surface properties and adsorption performance, as confirmed by first-principles calculations $[19,20]$. It is thus inferred that the unique nanoporous structure of the np-Pd is possibly responsible for the enhanced intrinsic activity.

The np-Pd/Al-fiber catalyst exhibits a CO conversion of $\sim 55 \%$, and a DMO selectivity of $\sim 95 \%$ for 150 hours test (Fig. 2B). The diffraction peak of Pd(200) (JCPDS 01-1201) is almost intact for the used catalyst after 150 hours test (XRD pattern in Fig. S11) suggesting the anti-sintering of the $\mathrm{np}-\mathrm{Pd}$. These results clearly indicate that the $\mathrm{np}-\mathrm{Pd} / \mathrm{Al}$-fiber catalyst is very stable. Moreover, in comparison with the catalysts reported in the literature, the np-Pd/Al-fiber has low $\mathrm{Pd}$ content and medium catalytic performance (Table S1). However, the used support of our microfibrous-structured Al-fiber possesses enhanced heat/mass transfer and low pressure drop compared to the common $\alpha-\mathrm{Al}_{2} \mathrm{O}_{3}$ support. 

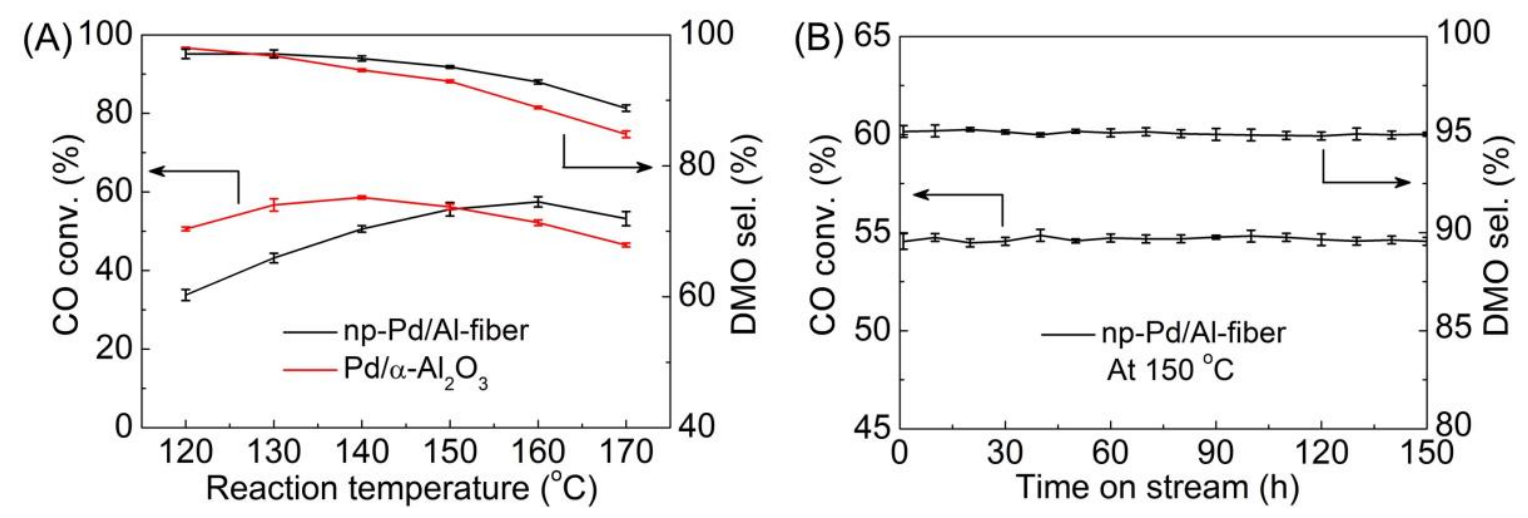

Fig. 2. (A) Conversion and selectivity as a function of reaction temperature (np-Pd/Al-fiber: 0.28 wt $\% \mathrm{Pd}, \mathrm{Pd} / \alpha-\mathrm{Al}_{2} \mathrm{O}_{3}: 0.26 \mathrm{wt} \% \mathrm{Pd}$ ) for the $\mathrm{CO}$ oxidative coupling to DMO. (B) Conversion and selectivity of the np-Pd/Al-fiber for 150 hours test. Reaction conditions: GHSV $=3000 \mathrm{~mL} \mathrm{~g}^{-1} \mathrm{~h}^{-1}$, $\mathrm{CO} / \mathrm{CH}_{3} \mathrm{ONO} / \mathrm{N}_{2}=14 / 10 / 76$ (volume), 1 bar. Note that each point is an average of three measurements (Fig. 2A) and five measurements (Fig. 2B) performed.

Table 1 Catalyst characteristics of the np-Pd/Al-fiber and $\mathrm{Pd} / \alpha-\mathrm{Al}_{2} \mathrm{O}_{3}$ catalysts ${ }^{\mathrm{a}}$.

\begin{tabular}{llllll}
\hline Sample & $D^{\mathrm{b}}$ & $d(\mathrm{~nm})^{\mathrm{b}}$ & $\mathrm{Pd}(\mathrm{wt} \%)^{\mathrm{c}}$ & ${\text { Surface Pd }\left(\mathrm{mol} \mathrm{g} \mathrm{cat}^{-1}\right)^{\mathrm{d}}}$ & $\mathrm{TOF}\left(\mathrm{s}^{-1}\right)^{\mathrm{e}}$ \\
\hline np-Pd/Al-fiber & 0.09 & 12 & 0.28 & $2.4 \times 10^{-6}$ & 1.2 \\
$\mathrm{Pd} / \alpha-\mathrm{Al}_{2} \mathrm{O}_{3}$ & 0.60 & 2 & 0.26 & $1.5 \times 10^{-5}$ & 0.2 \\
\hline
\end{tabular}

${ }^{\mathrm{a}}$ Reaction conditions: $140{ }^{\circ} \mathrm{C}, \mathrm{GHSV}=3000 \mathrm{~mL} \mathrm{~g}^{-1} \mathrm{~h}^{-1}, \mathrm{CO} / \mathrm{CH}_{3} \mathrm{ONO} / \mathrm{N}_{2}=14 / 10 / 76$ (volume), 1 bar.

${ }^{\mathrm{b}}$ Dispersion $(D)$ of Pd determined through pulse chemisorption of $10 \mathrm{vol} \% \mathrm{CO}$ with a stoichiometry of $\mathrm{CO} / \mathrm{Pd}=1$ and nanoparticle size $(d, \mathrm{~nm})$ obtained by the formula $(d=1.12 / D)[15]$.

${ }^{\mathrm{c}}$ Actual Pd content measured by ICP-AES analysis.

${ }^{\mathrm{d}}$ Surface Pd atoms estimated from actual Pd content and Pd dispersion $(D)$.

${ }^{\mathrm{e}} \mathrm{TOF}$ according to the $\mathrm{CO}$ conversion at $140{ }^{\circ} \mathrm{C}$ and surface $\mathrm{Pd}$ atoms.

\section{Conclusions}

We report the preparation of nanoporous palladium (np-Pd) catalyst on microfibrous-structured 
Al-fibers for the $\mathrm{CO}$ oxidative coupling to DMO. The microfibrous-structured np-Pd/Al-fiber catalyst from macro- to nanoscale is fabricated by a tailored spontaneous deposition via the galvanic replacement between $\mathrm{Pd}^{2+}$ and $\mathrm{Al}\left(2 \mathrm{Al}+3 \mathrm{Pd}^{2+} \rightarrow 2 \mathrm{Al}^{3+}+3 \mathrm{Pd}\right)$. For the catalyst with a low $\mathrm{Pd}$ content $(0.28 \mathrm{wt} \%)$, a CO conversion of $\sim 55 \%$ and a DMO selectivity of $\sim 95 \%$ are obtained for a feedgas of $\mathrm{CO} / \mathrm{CH}_{3} \mathrm{ONO} / \mathrm{N}_{2}\left(14 / 10 / 7.6\right.$, volume) at GHSV of $3000 \mathrm{~mL} \mathrm{~g}^{-1} \mathrm{~h}^{-1}$. Notably, the catalyst provides stable activity and selectivity through the 150 hours lifetime test. The np-Pd/Al-fiber catalyst shows four times larger intrinsic activity (i.e., turnover frequency) than the $\mathrm{Pd} / \alpha-\mathrm{Al}_{2} \mathrm{O}_{3}$ catalyst, which is attributed to the structure difference between the np-Pd with nanoligaments and the $\mathrm{Pd}$ nanoparticles present in the $\mathrm{Pd} / \alpha-\mathrm{Al}_{2} \mathrm{O}_{3}$ catalyst. Moreover, compared to the catalysts reported in the literature, our np-Pd/Al-fiber catalyst has the unique structure of $\mathrm{np}-\mathrm{Pd}$ with improved intrinsic activity, and shows enhanced heat/mass transfer, large permeability originated from the microfibrous-structured Al-fibers.

\section{Acknowledgements}

This work is supported by the China Postdoctoral Science Foundation (2017M622311), Fundamental Research Funds for the Central Universities (18CX02148A), Postdoctoral Research Project of Qingdao (BY20170209) and the Sino-French LIA “Zeolites”.

\section{References}

[1] W. Luc, F. Jiao, Acc. Chem. Res. 49 (2016) 1351-1358.

[2] J. Son, S. Cho, C. Lee, Y. Lee, J.H. Shim, Langmuir 30 (2014) 3579-3588.

[3] J. Zhang, C.M. Li, Chem. Soc. Rev. 41 (2012) 7016-7031.

[4] J. Zhang, Q. Bai, Z. Zhang, Nanoscale 8 (2016) 7287-7295.

[5] B.C. Tappan, S.A. Steiner, E.P. Luther, Angew. Chem. Int. Ed. 49 (2010) 4544-4565. 
[6] G. Zhao, Y. Liu, Y. Lu, Sci. Bull. 61 (2016) 745-748.

[7] R. Chai, Y. Li, Q. Zhang, G. Zhao, Y. Liu, Y. Lu, Catal. Commun. 70 (2015) 1-5.

[8] X. Du, D. Zhang, L. Shi, R. Gao, J. Zhang, Nanoscale 5 (2013) 2659-2663.

[9] C. Wang, J. Ding, G. Zhao, T. Deng, Y. Liu, Y. Lu, ACS Appl. Mater. Interfaces 9 (2017) 9795-9804.

[10] H. Yue, Y. Zhao, X. Ma, J. Gong, Chem. Soc. Rev. 41 (2012) 4218-4244.

[11] H. Yue, Y. Zhao, L. Zhao, J. Lv, S. Wang, J. Gong, X. Ma, AIChE J. 58 (2012) 2798-2809.

[12] S. Peng, Z. Xu, Q. Chen, Z. Wang, D. Lv, J. Sun, Y. Chen, G. Guo, ACS Catal. 5 (2015) 4410-4417.

[13] S. Peng, Z. Xu, Q. Chen, Y. Chen, J. Sun, Z. Wang, M. Wang, G. Guo, Chem. Commun. 49 (2013) 5718-5720.

[14] X. Zhao, Q. Lin, W. Xiao, Appl. Catal. A 284 (2005) 253-257.

[15] C. Wang, L. Han, P. Chen, G. Zhao, Y. Liu, Y. Lu, J. Catal. 337 (2016) 145-156.

[16] C. Wang, L. Han, Q. Zhang, Y. Li, G. Zhao, Y. Liu, Y. Lu, Green Chem. 17 (2015) 3762-3765.

[17] T. Fujita, L. Qian, K. Inoke, J. Erlebacher, M. Chen, Appl. Phys. Lett. 92 (2008) 251902-251904.

[18] X. Zhang, P. Guan, L. Malic, M. Trudeau, F. Rosei, T. Veres, J. Mater. Chem. A 3 (2015) 2050-2056.

[19] M. Hakamada, H. Nakano, T. Furukawa, M. Takahashi, M. Mabuchi, J. Phys. Chem. C 114 (2009) 868-873.

[20] S. Cherevko, N. Kulyk, C. Chung, Nanoscale 4 (2012) 103-105. 